\title{
Cloud Computing of E-learning
}

\author{
Tamara Almarabeh ${ }^{1} \&$ Yousef Kh. Majdalawi ${ }^{1}$ \\ ${ }^{1}$ Department of Computer Information Systems, The University of Jordan, Jordan \\ Correspondence: Tamara Almarabeh, Department of Computer Information Systems, The University of Jordan, \\ Jordan. E-mail: t.almaraabeh@ju.edu.jo
}

Received: June 19, 2018

Accepted: June 25, 2018

Online Published: July 9, 2018

doi:10.5539/mas.v12n8p11

URL: https://doi.org/10.5539/mas.v12n8p11

\begin{abstract}
With considerable improvement in Information and Communication Technology (ICT) field, many areas of our lives have been affected, including the learning environmentE-learning is one such inventions and is linked to the use of electronic methods to support the E-learning process, which has become increasingly popular and has become a strong trend due to the enormous benefits it offers to learning environments. However, E-learning systems and its management require huge investments in information technology, and many educational institutions don't have enough budget to afford the cost, therefore cloud computing is the finest solution. It provides an effective mechanism which can allow of building a new mode of E-learning system. This paper, discusses the features of the E-learning system, describes the strategy of Cloud computing, and analyzes the impact of using Cloud Computing in E-learning.
\end{abstract}

Keywords: e-learning, ICT, cloud computing, NIST

\section{Introduction}

Nowadays, ICTs play an essential role in the learning field. There are many models to get knowledge through Internet. One of the most favorable models in education field is E-learning. It indicates to the use of ICT in the network, allowing new opportunities for developing the education that have a strong effect on learning and teaching. Currently, no one can deny the popularity of E-learning in learning and teaching fields, regardless of time and space barriers (Dong, \& Huang, 2011).

Other advantages have helped to accept E-Learning systems in countries including: the ease access to ICT, enormous growth in data, users, and resources (i.e. hardware and software), increasing flexibility, ease of access, convenience and availability of variety of courses, and reducing the training cost (Ajadi et.al, 2008, Fern'andez et.al, 2012). Whilst there are many educational institutions cannot be adopting E-learning platform due to its huge investments in IT infrastructure (i.e. hardware and software) (Paul \& Santhi, 2014).

To solve these problems, a key model has been emerging recently in the present century which is cloud computing. It is a new model for E-learning systems that providing suitable, on-demand access to a centralized shared pool of computing resources that can be deployed with great performance and minimal management overhead (El-Sofany et.al, 2013).

This model is a new technology which can improve universities functions in terms of students and academic staff services, and institutions themselves. Currently, the cloud computing is a trend that can solve the contradiction between the need to act quickly when experimenting new ideas and the slow traditional processes of planning and developing. The basic idea of cloud computing is to connect the computing resources as a service consumed by people, rather than a product that runs on their individual computers (Rădulescu, 2014).

This research is organizing as follows: E-learning architecture i.e. definition and its advantages have been explained in section 2. Cloud computing architecture has been discussed in section 3. Section 4 describes how can the cloud computing provide the E-learning systems with many services, and the conclusion in section 5.

\section{E-learning Architecture}

E-learning is an electronic learning, think of "E" as "Extended, Engaging, Energetic, and Exciting" learning (Luskin, 2012). Nowadays, it is widely used at different levels of education, like universal courses, firm trainings ...etc. With the advent of handheld wireless devices (i.e. mobile phones, tablets and iPads), new terms are appeared such as "M-learning, which means the learner can learn in various environments using portable 
devices rather than being restricted to a classroom or to a desk.

Liu in his research (Liu, 2010) provides the following definition of E-learning: "E-learning uses the Internet or other digital content for learning and teaching activities, which takes full advantage of modern educational technology provided with a new mechanism of communication and resource-rich learning environment to achieve a new way of learning".

Many research studies have been addressed the various issues that are related to E-learning in higher education system. Some of researchers defined E-learning (OECD, 2005), Sambrook, 2003), as "communication and learning activities through computers and networks (or via electronic means)". Fry (Fry, 2000) provided more specific definition; "delivery of training and education via networked interactivity and a range of other knowledge collection and distribution technologies." Wild, Griggs and Downing (Wild et.al, 2002) also had the same definition as Fry's - they defined E-learning as "the creation and delivery of knowledge via online services in the form of information, communication, education and training". Bleimann (Bleimann, 2004) stated that E-learning is a self-directed learning based on technology, especially web-based technology.

As shown in Figure 1, the architecture of an E-learning system is distributed system, consisting of two essential components: hardware and software. The hardware can be servers, communication infrastructure, and client device which can be PC, mobile, or tablet. The software consists of database, applications, and client application which can be dedicated application or web browser (Pocatil, 2010).

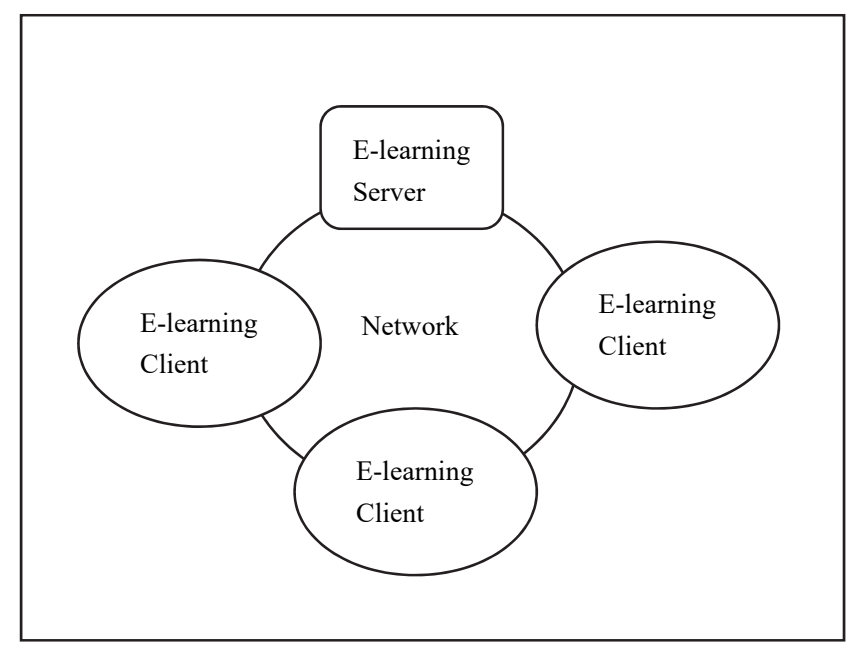

Figure 1. E-learning System

E-learning includes communication tools (i.e. synchronous and asynchronous), learners tracking, and assessment and collaboration techniques (Sneha \& Nagaraja, 2013). E-learning is enhanced learning process based on ICT tools that are used to improve the online activities. There are basically four types of E-learning systems: Learning Support System (LSS), Learning Content Management System (LCMS), Learning Management System (LMS), and Learning Design System (LDS) (Ismail, 2002).

Based on the literature review (Allen, 2011, Roy and Raymond, 2005) the E-learning has many advantages, some of them are listed below:

- Saving money: In E-learning, there is production and small implementation costs only, no cost for production, set up, delivery, nor travelling.

- Accessibility: The students can access the material anywhere and anytime without worrying of missing important information.

- Affectivity: The E-learning has different learning styles and the students can choose their learning styles through variety of media (i.e. presentations, video, audio, etc.). In addition to, the student can replay some segments.

The review of some previous work in E-learning field (Almarabeh et.al, 2014, Guoli \& Wanjun, 2010, Karim \& Goodwin, 2013, Kerres \& Witt, 2003) shows the resources of E-learning systems are the most important challenges facing the universities. It is important to understand that the cost in E-learning related to the maintenance of hardware (servers, computers, data centers, computing centers ...), and software which means the university has to pay for the site license, installation, and the technical support. (Kwan et.al, 2008, Arabasz et.al, 2003). 
There are at least two users involved in an E-learning system: the teachers (i.e. uploading the course description, assignments and projects, assessing them and sending feedback, preparing exams and communicate with the students through forums...etc.), and the students (i.e. taking the courses online, downloading and uploading the assignments after solving, and taking exams...etc.).

\section{Cloud Computing Architecture}

Cloud computing is an important modern term in many fields. It doesn't refer to specific technology so it has many definitions (Schubert et.al, 2010). IEEE Computer Society defined Cloud computing as: "A paradigm in which information is constantly stored in servers on the Internet and cached temporarily on clients that include desktops, entertainment centers, computers, notebooks, handhelds, etc." (Kho, 2009). It provides the delivery of computing as a service not as a product, where by shared resources; software and information are produced to computers and other devices as a metered over a network.

The National Institute of Standards and Technology (NIST) defined it as: (The National Institute of Standards and Technology, 2011): "Cloud computing is a model for enabling convenient to access to networks and applications quickly, common set of configurable computing resources (e.g., networks, servers, storage and applications) that can work with little or interfere with the service provider to provide or be released immediately." Berkeley RAD Lab provided another definition (Armbrust et.al, 2009) is "cloud computing refers to both the applications delivered as services over the Internet and the hardware and systems software in the datacenters that provide those services. The services themselves have long been referred to as Software as a Service (SaaS), so we use that term. The datacenter hardware and software is what we will call the cloud".

As shown in figure 2 , the cloud computing has three widely referenced service models.

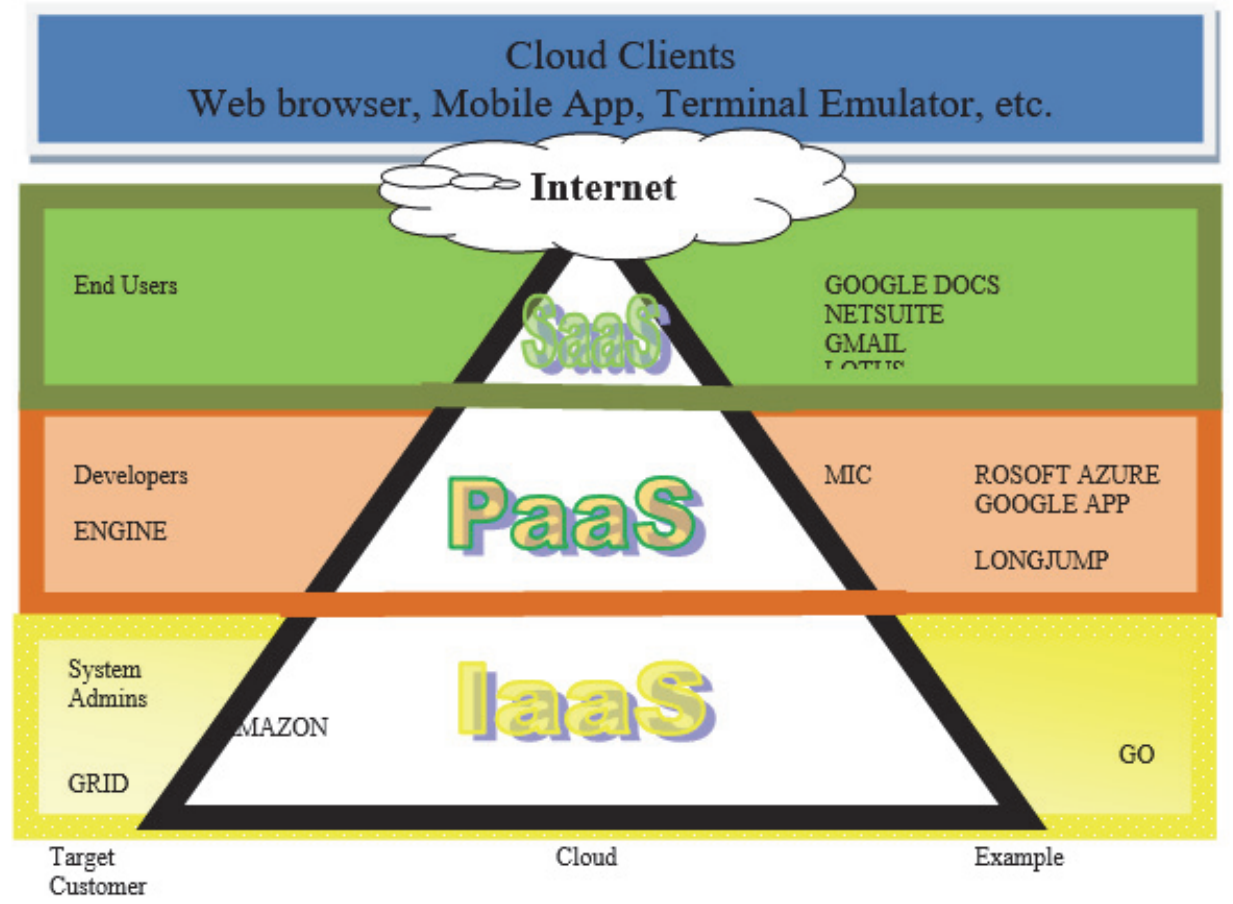

Figure 2. Models of Cloud Computing

1) Infrastructure as a Service (IaaS): The resources (servers and storage) are offered as services to customers so the businesses rent the resources rather than spending money to buy.

2) Platform as a Service (PaaS): Provides required platform to develop and customize applications.

3) Software as a Service (SaaS): Software applications are offered as services, like: Email, customer relationship management (CRM), instant messaging (IM), and office applications.

In addition to these service models, four deployments have been added (Almarabeh \& Majdalawi, 2017):

1) Public Cloud: the storage, cloud applications are made available to the public by a service provider. These services can be free or offered on pay-per-use. 
2) Private Cloud (also known as internal cloud): means the cloud infrastructure specified for a particular organization which it is not shared with other organizations. Private clouds are more expensive but also more secure when compared to public clouds.

3) Community Cloud: means sharing computing infrastructure between several organizations from a specific community.

4) Hybrid Cloud: These Clouds are a composition of two or more clouds (i.e. public, private, and community) to take the advantages of multiple deployment models such as increasing the flexibility of computing. The costs are spread over fewer users than public cloud (but more than private cloud).

The models of cloud computing offer enormous benefits to institutions such as reduced infrastructure costs, unlimited data storage, recovery, backup, and ease access to information. On the other hand, the cloud computing has disadvantages as follows (Micheal, 2009):

$\checkmark \quad$ The Internet connection: The internet is an essential component for cloud computing. In some regions there is no internet which means the user can't access anything (i.e. applications, documents... etc.). Therefore, using the cloud computing there is impossible.

$\checkmark \quad$ Limit the accessibility: In the regions that suffer low speed connections (i.e. Dial-up services), cloud computing will degrade the performance because it requires stable and fast connection to work with the large files and web-applications that need a lot of bandwidth to download.

$\checkmark$ Data security: In cloud computing, data is stored in the cloud. This means the data is just as secure as the cloud is. If an unauthorized user can access the cloud, he/she will also have access to stored data in the cloud. In addition to the need for backups.

$\checkmark$ Cost: On the long term, the data center subscription fee can be more expensive than buying the hardware; also the data will be accumulated massively to make it difficult to control.

\section{Relationship between E-learning and Cloud Computing}

In the present information age, ICT plays an important role in transforming how knowledge and skills are transferring to students rather than traditional face-to-face approach. There is need to redesign the delivery of educational system in response to the changing world as influenced by advancement in ICT (Baniwal, 2013).

These two systems together provide an environment where the user only requires a portable device which can be mobile, tablet, PC, etc. The main elements of E-learning are hardware, software, and platform. The cloud computing can facilitates them. Users can get/put data on the cloud from any place at any time. The primary characters tics of the relationship between them: resource pooling, on-demand self-service, broad network access, etc.

Many universities can't run the E-learning system due to the needed infrastructure and the resources. This is the reason of why Moodle and Blackboard have versions of cloud oriented base applications.

The trend towards the cloud computing because of low costs in terms of: development and technical support teams cost, periodic backup cost, and total project expenses. (Ahmed \&Fouad, 2015, Akin et.al, 2014, Al Zoube, 2009, Rao, 2010).

A study conducted by (Ahmed \&Fouad, 2015) showed a comprehensive comparison between E-learning system before and after moving onto Cloud to see the contribution of E-learning standards with the Cloud standards. The result supports the moving on to Cloud Computing environment because it is used as solutions to delivery of computing as a service rather than a product. Table 1 shows the comparison between the traditional E-learning architecture and E-learning architecture based on Cloud computing (Masud \&Huang, 2009, Gamundan et.al, 2013, Pocatilu et.al, 2009).

Table 1. From Traditional E-learning Network to Cloud E-learning

\begin{tabular}{lll}
\hline Service & Traditional E-learning & Cloud E-learning \\
\hline Acquisition Model & Buy Assets & Buy Service \\
& Build Technical Architecture & Architecture Include \\
Business Model & Pay For Assets & Pay for Use \\
& Administrative Overhead & Reduced Admin function \\
Access Model & Internal Networks & Over the Internet \\
& Corporate Desktop & Any Device \\
\hline
\end{tabular}




\begin{tabular}{lll}
\hline Technical Model & Single tenant, non- shared & Multi-tenant, Scalable, and \\
& Elastic \\
Static & Dynamic \\
Delivery Model & Costly, Lengthy Deployments & Reduced Deployments time \\
& Land and Expand Staffing & Fast ROI (Return On Investment) \\
\hline
\end{tabular}

E-learning cloud is "a migration of cloud computing technology in the field of E-learning, which is a future Elearning infrastructure, including all the necessary hardware and software computing resources engaging in Elearning. After these computing resources are virtualized, they can be afforded in the form of services for educational institutions, students and businesses to rent computing resources" (Poonam \& Sulke, 2014). Figure 3 shows E-learning cloud architecture.

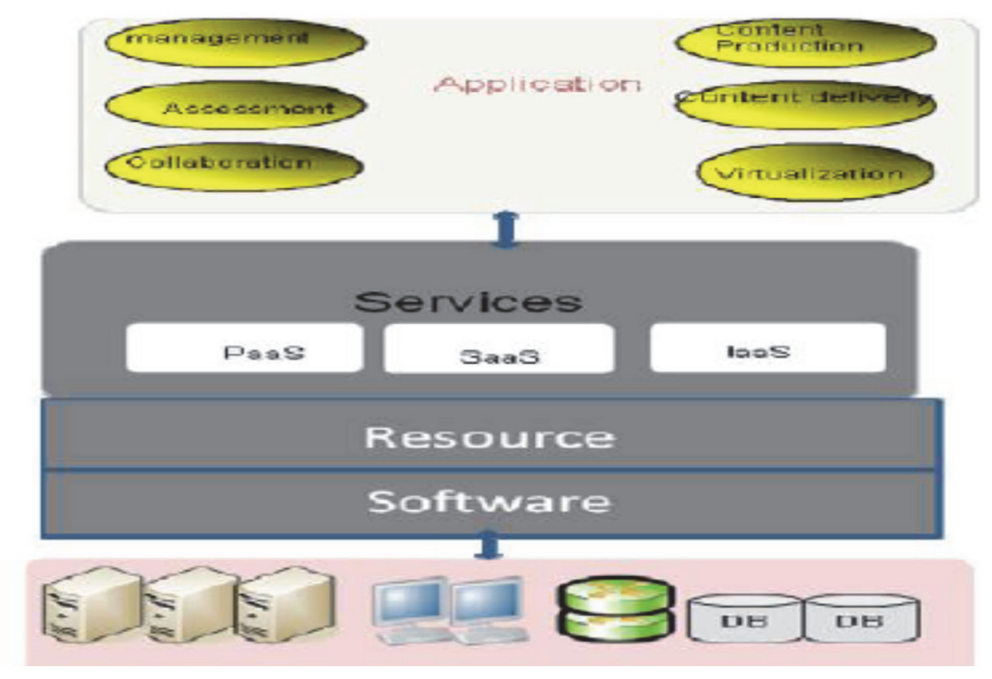

Figure 3. E-learning Cloud Architecture

The architecture can be divided into five layers:

1) Infrastructure layer: This layer is located in the lowest level of cloud service middleware like physical memory and CPU. It is a dynamic and scalable physical host pool.

2) Software resource layer: offers a unified interface for E-learning developers, composed of Operating system and middleware.

3) Resource management layer: This layer achieves loose coupling of software and hardware resources.

4) Service layer: It is containing three levels of services (software as a service (SaaS), platform as a service (PaaS), and infrastructure as a service (IaaS)).

5) Application layer: Provides content production, content delivery, virtual laboratory, collaborative learning, assessment and management features.

The E-Learning systems face many challenges, and many previous researches provide some possible solutions to overcome these challenges (Poonam \& Sulke, 2014, Viswanath et.al, 2012, Patel \& Chaube, 2014, Al Ajmi, 2014, Dong et al., 2009):

$\checkmark \quad$ Lack of appropriate infrastructure: Many universities can't adopt the E-learning systems because E-learning needs rich multimedia and high resource requirements like storage, and bandwidth. In Cloud computing, data is created and accessed in the cloud, so no need for users to have digital devices (mobile, PC, Tablet) with large memory or high specifications. They can run the applications from cloud through their devices. Regarding the universities, they need to pay for each use and for the space they need only.

$\checkmark \quad$ Lack of maintenance and technical support: Many universities do not have highly qualified staff to support their own infrastructure and respond to network interruptions or security threats. In cloud computing there is centralized infrastructure which will reduce the needed time for responding to the issues. In addition to, Elearners will get the updated programs immediately because the programs are updated in the cloud. 
$\checkmark \quad$ Change Management: The changing to an online system like E-learning will effects on all users like teachers, students, and technical staff. So the changing process isn't easy and the users need to recognize the value of such system and utilize it in their daily lives. Clouds provide wider access to E-learning users (i.e. access from anywhere), and the content of E-learning can be deployed and distributed quickly.

There is an important issue regarding security is cloud computing where the remote servers can be crash for some reason without warnings. Regarding this point, no need to worry about because the cloud computing provides some central security benefits for users and organizations that are using/developing E-learning as follows (Aljenaa, 2011):

$\checkmark \quad$ It is impossible to locate the machine that stores important data (i.e. exam questions and results).

$\checkmark \quad$ The primary part of the applications and data is stored into the cloud so it is not a major problem to lose the cloud client. Any new client can be connected quickly, and the observation of data access is easier than the traditional ways.

$\checkmark \quad$ Quick replacement of a compromised cloud located server without large costs or damages. It is very easy to create a clone of a virtual machine so the cloud downtime is expected to be reduced highly.

\section{Conclusion}

E-learning is a rapid and effective way to spread knowledge to learners in all countries in the world but need huge investments in IT infrastructure. The Cloud Computing is an attractive solution to provide services with minimal cost. It can reduce the costs due to low requirements of hardware and software, less need for onsite maintenance, and easy deployment across multiple locations. The limitations of cloud computing are represented by internet low speed which can adversely affect the performance of services in E-learning. Day by day, the internet speed and stability are continuing to be improved, therefore the popularity of cloud computing will be supported.

\section{References}

Ahmed, A., \& Fouad, F. (2015). Comparative Analysis for Cloud Based e-learning. International Conference on Communications, Management, and Information Technology (Iccmit'2015) Book Series: Procedia Computer Science.

Ajadi, T. O., Salawu, I. O., \& Adeoye, F. A. (2008). E-learning and distance education in Nigeria. Turkish Online Journal of Educational Technology-TOJET, 7(4), 61-70

Akin, O. C., Matthew, F. T., \& Comfort, Y. D. (2014). The Impact and Challenges of Cloud Computing Adoption on Public Universities in Southwestern Nigeria. (IJACSA). International Journal of Advanced Computer Science and Applications, 5(8).

Al Ajmi, M. F., Khan, S., \& Khan, I. (2014). Cloud Computing Utilization for E-Learning Pharmaceutical System. International Journal of Scientific \& Technology Research, 3(3).

Al Zoube, M. (2009). E-Learning on the Cloud. International Arab Journal of e-Technology, 1(2), 58-64.

Aljenaa, E., Al-Anzi, F. S., \& Alshayeji, M. (2011). Towards an efficient e-learning system based on cloud computing. Proceedings of the Second Kuwait Conference on e-Services and e-Systems. ACM. 2011 April; p. 13. https://doi.org/10.1145/2107556.2107569

Allen, M. W. (2011). Michael Allen's 2012 E-learning annual. Pfeiffer. ISBN 978-0-470-91382-6.

Almarabeh, T., \& Majdalawi, Y. Kh. (2017). General framework for Cloud Computing in higher education: definition, models, opportunities, and success. International Journal of Instructional Technology and Distance Learning, 14(12).

Almarabeh, T., Mohammad, H., Yousef, R., \& Majdalawi, Y. (2014). The University of Jordan E-Learning Platform: State, Students' Acceptance and Challenges. Journal of Software Engineering and Applications, 7, 999-1007. http://dx.doi.org/10.4236/jsea.2014.712087

Arabasz, P., Pirani, J., \& Fawcett, D. (2003). Supporting e-learning in higher education. Retrieved from http://net.educause.edu

Armbrust, M., Fox, A., Griffith, R., Joseph, A., Katz, R., Konwinski, A., ... Zaharia, M. (2009). Above the Clouds: A Berkeley View of Cloud Computing. UC Berkeley Reliable Adaptive Distributed (RAD) Systems Laboratory, Berkeley. Retrieved March 2, 2018, from www.eecs.berkeley.edu/Pubs/TechRpts/2009/EECS2009-28.pdf

Baniwal, R. (2013). Application of cloud computing in different areas. International Journal of Computer Science 
\& Communication, 4(2), 174-176.

Bleimann, U. (2004). Atlantis University: a new pedagogical approach beyond E-learning. Campus-wide Information Systems, 21(5), 191-195.

Dong, B., Zheng, Q., Yang, J., Li, H., \& Qiao, M. (2009). An e-learning ecosystem based on cloud computing infrastructure. in Advanced Learning Technologies, 2009. ICALT 2009. Ninth IEEE International Conference on. 2009. IEEE. https://doi.org/10.1109/ICALT.2009.21

Dong, L. Y., \& Huang, R. (2011). Designing collaborative E-learning environments based upon semantic wiki: from design models to application scenarios. Educational Technology \& Society, 14(4), 49-63.

El-Sofany, H., Al Tayeb, A., Alghatani, K., \& El-Seoud, S. (2013). The impact of cloud computing technologies in E-learning. International Journal of Emerging Technologies in Learning, 8(1), $37-43$. http://dx.doi.org/10.3991/ijet.v8iS1.2344

Fern'andez, A., Peralta D., Herrera F., \& Ben'itez, J. M. (2012). An overview of E-learning in cloud computing. Proceedings of Learning Technology for Education in Cloud (LTEC '12), pp. 35-46.

Fry, K. (2000). Forum focus and Overview, the business of E-learning: Bringing your organization in the knowledge Economy, Telcam Group, University of Technology, Sydney.

Gamundani, A. M., Rupere, T., \& Nyambo, B. M. (2013). A cloud computing architecture for e-leaning platform, supporting multimedia content. International Journal of Computer Science and Information Security, 11(3), 92-99.

Guoli, Z., L. (2010). Wanjun, The applied research of cloud computing platform architecture in the E-Learning area, In Computer and Automation Engineering (ICCAE), 2010. The 2nd International Conference on. 2010. IEEE. https://doi.org/10.1109/ICCAE.2010.5451399

Ismail J. (2002). The design of an E-learning system: Beyond the hype. Internet and Higher Education. 4. pp. 329336. Retrieved March 2018, 20 https://pdfs.semanticscholar.org/8dba/ae61f9ecd51fdbfe264f97bfbe25cda83520.pdf

Karim, F., \& Goodwin, R. (2013), Using cloud computing in E-learning systems. International Journal of Advanced Research in Computer Science \& Technology, 1(1), 65-69.

Kerres, M., \& Witt, C. D. (2003). A didactical framework for the design of blended learning arrangements. Journal of Educational Media, 28(2-3), 101-113.

Kho, N. D. (2009). Content in the Cloud. E Content Mag, 32, 26-30.

Kwan, R., Fox, R., Chan, F., \& Tsang, P. (2008), Enhancing learning through technology: research on emerging technologies and pedagogies. New Jersey: World Scientific. ISBN-13978-981-279-944-9 ISBN-10981-279944-3

Liu, C. H. (2010). The comparison of learning effectiveness between traditional face-to-facE-learning and Elearning among goal oriented users, in Digital Content, Multimedia Technology and its Applications (IDC), 2010 6th International Conference on. 2010. IEEE.

Luskin, B. (2010). Think "Exciting": E-Learning and the Big "E", Educause Review Online.

Masud, M. A. H., \& Huang, X. (2012). An E-learning System Architecture based on Cloud Computing, World Academy of Science. Engineering and Technology International Journal of Information and Communication Engineering, 6(2).

Micheal, M. (2009). Cloud computing: Web- based applications that change the way you work and collaborate online. 2009, USA: Que ISBN-13: 978-0-7897-3803-5 ISBN-10: 0-7897-3803-1. Retrieved March 2, 2018, from http://ptgmedia.pearsoncmg.com/images/9780789738035/samplepages/ 0789738031_Sample.pdf

OECD. (2005). Organisation for Economic Co-Operation and Development, E-learning in tertiary education. Published December 2005. Retrieved March 2, 2018, from http://www.oecd.org/education/ceri/35991871.pdf

Patel, M., \& Chaube, A. R. (2014). Literature review of recent research on Cloud Computing in Education. International Journal of Research, 1(6).

Paul, C. J., \& Santhi, R. (2014). A study of E-learning in cloud computing. International Journal of Advanced Research in Computer Science and Software Engineering, 4(4), 729-734.

Pocatil, P. (2010). Cloud Computing Benefits for E-learning Solutions. Oeconomics of Knowledge, 2(1), 9-14. 
Pocatilu, P., Alecu F., \& Vetrici, M. (2009). Using cloud computing for E-learning systems, Proceedings of the 8th WSEAS international conference on Data networks, communications, computers, p.54-59, November 07-09, 2009, Baltimore, MD, USA.

Poonam, R. M., \& Sulke, S. R. (2014). Review Paper on E-learning Using Cloud Computing. International Journal of Computer Science and Mobile Computing, 3(5), 1281-1287.

Rădulescu, Ș. A. (2014). A perspective on E-learning and cloud computing. Procedia-Social and Behavioral Sciences, 141, 1084-1088.

Rao, N. M., Sasidhar, C., \& Satyendra, K. V. (2010). Cloud Computing Through Mobile-Learning. International Journal of Advanced Computer Science and Applications, 1(6).

Roy, A., \& Raymond, L. (2005). E-learning in support of SMEs: Pipe dream or reality. Proceedings of 5th European Conference on E-learning (pp. 283).

Sally. S. (2003). E-learning in small organisations. Education + Training, 45(8)/9, 506-516. https://doi.org/10.1108/00400910310508892

Schubert, L., Jefferey, K., \& Neidecker-Lutz, B. (2010). The Future of Cloud Computing: Opportunities for European Cloud Computing beyond 2010, Public Version 1.0. Retrieved from http://cordis.europa.eu/fp7/ict/ssai/docs/cloud-report-final.pdf.

Sneha, J. M., \& Nagaraja, G. S. (2013), Virtual learning environments: a survey. International Journal of Computer Trends and Technology, 4(6), 1705-1709.

The National Institute of Standards and Technology, Published September 2011. Retrieved March 2, 2018, from http://csrc.nist.gov/publications/nistpubs/800-145/SP800-145.pdf

Viswanath, D. K., Kusuma, S., \& Gupta, S. K. (2012). Cloud Computing Issues and Benefits Modern Education. Global Journal of Computer Science and Technology Cloud \& Distributed, 12(10), 15-19.

Wild, R. H., Griggs, K. A., \& Downing, T. (2002). A framework for E-learning as a tool for knowledge Management. Industrial Management \& Data Systems, 102(7), 371-380.

\section{Copyrights}

Copyright for this article is retained by the author(s), with first publication rights granted to the journal.

This is an open-access article distributed under the terms and conditions of the Creative Commons Attribution license (http://creativecommons.org/licenses/by/4.0/). 